\title{
Dança e deficiência: uma revisão bibliográfica em teses e dissertações nacionais
}

\author{
Patricia Rossi* \\ Mey de Abreu van Munster ${ }^{* *}$
}

\begin{abstract}
Resumo: Este estudo tem como objetivo identificar e analisar a produção científica acerca da dança para pessoas com deficiência em teses e dissertações nacionais. Os resultados demonstraram: aumento na produção nos últimos cinco anos; prevalência de estudos junto à população de adultos com deficiência física; predominância de pesquisas envolvendo estudo de caso e Laban como aporte teórico; quanto ao eixo temático, prepondera o processo de ensino-aprendizagem da dança para as pessoas com deficiência; é dada maior evidência à dança contemporânea e dança em cadeira de rodas. Assim, foi possível reconhecer as principais tendências científicas envolvendo a interface dança e pessoas com deficiência.
\end{abstract}

Palavras-chave: Dança. Deficiência. Produção científica.

\section{INTRODUÇÃo}

Pesquisas envolvendo a interface "dança e deficiência" tiveram início, no Brasil, na década de 80, e demonstram um aumento, sobretudo nos últimos anos. A origem e o crescente interesse acadêmico de diversos campos científicos por essa área podem estar relacionados com a instituição de políticas públicas e a promulgação de leis direcionadas à educação e à inclusão de pessoas com deficiência na sociedade. Tais apontamentos corroboram com os estudos de Freire (2001), que indicam que novas propostas de trabalho direcionado para pessoas com deficiência vêm sendo desenvolvidas com a finalidade de explorar e respeitar cada corpo.

\footnotetext{
"Mestranda em Educação Especial, Universidade Federal do São Carlos, São Carlos-SP, Brasil. E-mail: patriciarossi.pr@hotmail.com

"Professora do Programa de Pós-Graduação em Educação Especial, Universidade Federal do São Carlos, São Carlos-SP, Brasil. E-mail: mey@ufscar.br
} 
Além das políticas que foram orientadas para a inclusão de pessoas com deficiência física, visual, intelectual e auditiva ${ }^{1}, 0$ aumento desses estudos parece estar relacionado aos benefícios a essa população decorrentes da dança.

De acordo com Mauerberg-deCastro (2005), os benefícios que a dança pode proporcionar às pessoas com deficiência envolvem aspectos motores, intelectuais, psicológicos e sociais, pois: facilita o desenvolvimento, a reabilitação e/ou a reeducação do gesto motor; relaciona e desenvolve os aspectos motores, melhorando a postura, a coordenação, o ritmo, a movimentação articular e o corpo como um todo; proporciona melhora na autoconfiança e na imagem corporal; e aprimora a comunicação, a cooperação e a inter-relação pessoal, promovendo a qualidade de vida.

Em seu estudo sobre dança para pessoas com deficiência física, Ferreira (2000) demonstra que há contribuições significativas e positivas para essas pessoas, pois: proporciona diferentes possibilidades de movimentos, indicando vias de solução de problemas; desenvolve o autoconhecimento, influenciando na descoberta das possibilidades de transformações sociais, e explora várias formas de expressão e de comunicação. Assim, a dança proporciona às pessoas com deficiência a ampliação do conhecimento acerca do movimento e a descoberta de habilidades motoras específicas que auxiliam no cotidiano, além da sua relação emocional com o movimento (FERREIRA; FERREIRA, 2004).

As propostas de dança envolvendo pessoas com deficiência vêm sendo disseminadas em diferentes contextos (educacional, de reabilitação, artístico e esportivo), com finalidades diversas (pedagógica, terapêutica, performática e competitiva), além de abarcar diferentes deficiências, tais como a física, a visual, a auditiva e a intelectual.

O contexto envolve "onde" se insere a dança: na escola (contexto educacional); em clínicas/institutos de fisioterapia ou de

\footnotetext{
'Segundo os dados do Censo de 2010 (INSTITUTO BRASILEIRO DE GEOGRAFIA E ESTATÍSTICA, 2013), as pessoas com deficiência física, auditiva, visual e/ou intelectual representam $23,9 \%$ da população brasileira.
} 
reabilitação (contexto de reabilitação); em grupos profissionais, amadores, academias de dança, espetáculos ou festivais de dança (contexto artístico); ou em locais que proporcionam as competições de dança e enfatizam o alto rendimento do bailarino/atleta (contexto esportivo). Já a finalidade envolve "o porquê" essa dança está sendo desenvolvida, com que propósito, sendo destacadas: a pedagógica, envolvendo os aspectos de ensino e aprendizagem da dança para os alunos; a terapêutica, envolvendo a reabilitação de gestos motores; a performática, envolvendo o desempenho do bailarino com deficiência ao dançar (expressão, movimento), e a competitiva, envolvendo o alto rendimento do bailarino/atleta em competições.

No contexto educacional, observa-se o predomínio de finalidades pedagógicas, sendo identificados estudos envolvendo a dança e pessoas com deficiência física (BERNABÉ, 2001), deficiência visual (FREIRE, 2005), deficiência auditiva (JOSEPH, 2010) e deficiência intelectual (SOUZA, 2011). Esses estudos, de modo geral, demonstram a preocupação em envolver a ação do professor no sentido de despertar e orientar o aluno para o movimento livre e para técnicas de diversas danças, desde que haja uma ação consciente, reflexiva e que respeite a individualidade de cada aluno.

Esses autores que abordam a dança em um contexto educacional com finalidade pedagógica, em sua maioria, empregam como aporte teórico Rudolf Laban, que se refere à dança como um meio para educar, proporcionando movimentos naturais e espontâneos e desenvolvendo a capacidade de dançar e relacionarse com o mundo. Afinal, segundo o autor, o movimento é um elemento básico da vida e deve ser orientado e estruturado a fim de proporcionar o desenvolvimento de cada um, justificando, assim, a educação por meio da dança (LABAN, 1990).

No âmbito da reabilitação, sobrepõe-se a finalidade terapêutica. Em seu estudo, Machado (2010) disserta que a dança pode ser um agente importante para a melhoria da qualidade de vida das pessoas com deficiência física, pois atua como integradora corporal viabilizando 
o ajuste postural e funcional. Com isso, a dança influencia de forma positiva na regulação e na orientação dos mecanismos essenciais para o movimento, além de melhorar aspectos sociais e emocionais.

No contexto artístico, sobressaem os aspectos performáticos, relacionados ao desempenho que o bailarino com deficiência apresenta ao dançar. O estudo de Correa (2007), com base em uma análise do espetáculo Judite quer chorar, mas não consegue!, desenvolvida pelo bailarino Edu Oliveira (usuário de cadeiras de rodas), dissertou sobre a maneira como a dança em cadeira de rodas pode proporcionar discussões acerca do corpo com deficiência e a construção de sua imagem na sociedade, visando o processo de inclusão. Além de romper com os modelos homogêneos de corpos perfeitos, demonstra a complexidade entre o corpo do bailarino cadeirante e suas potencialidades em dança.

A dança envolvendo pessoas com deficiência também se estabelece no contexto esportivo. A Dança Esportiva Cadeira de Rodas (DECR) teve início no Brasil a partir de 1990, sendo uma modalidade voltada, especificamente, às pessoas com deficiência física usuárias de cadeira de rodas, tendo como finalidade a competição e o alto rendimento dos bailarinos (FERREIRA; FERREIRA, 2004). Estudos como os de Paula (2010) evidenciam elementos que devem ser trabalhados para aumentar o rendimento dos bailarinos/atletas e demonstram a necessidade do aprimoramento da programação e do planejamento do treinamento físico específico para cada um deles, visando às necessidades acerca de cada deficiência. Quanto ao contexto esportivo e demais deficiências (visual, auditiva e intelectual) não foram encontrados estudos envolvendo essas categorias acerca da Dança Esportiva.

Ressalta-se que, embora haja uma relação maior entre o contexto educacional e a finalidade pedagógica; o contexto de reabilitação e a finalidade terapêutica; o contexto artístico e a finalidade performática e o contexto esportivo e a finalidade competitiva e de alto rendimento, pode haver uma sobreposição entre 
esses contextos e finalidades. Assim, um contexto possibilita o envolvimento de diversas finalidades, e as finalidades podem ser desenvolvidas em diversos contextos.

Essa versatilidade da dança, capaz de envolver diferentes contextos e finalidades, a caracteriza como agente interdisciplinar, pois pode abranger duas ou mais áreas do conhecimento. Um exemplo seria a interface entre a educação, o esporte e a saúde, áreas cujas relações, segundo Schmitt et al. (2006), abrangem métodos e estruturas teóricas com a finalidade de proporcionar um enriquecimento mútuo.

Independentemente do contexto (educacional, de reabilitação, artístico ou esportivo) e da finalidade (pedagógica, terapêutica, performática ou competitiva) em que/como a dança será desenvolvida, os autores estudados apontam a importância da atenção à organização adequada do programa, respeitando sempre a individualidade de cada um. Pedrinelli e Verenguer (2008) destacam a necessidade de proporcionar um ambiente favorável à aprendizagem e ao encorajamento da autossuperação.

Segundo Freire (2001), um programa de dança torna-se eficiente quando: desenvolve a consciência integral de um indivíduo; centraliza corpo, mente e emoção; amplia os repertórios de movimento; facilita o autoconhecimento do corpo por meio da interação social; observa e analisa o movimento humano; considera a singularidade de cada corpo; reproduz e divulga o conhecimento a partir da experiência.

Com isso, a partir desses referenciais, surgiram as seguintes questões de pesquisa: Quais são as características dos estudos envolvendo a interface "dança e deficiência" quanto à população, abordagens metodológicas, aporte teórico, conteúdos (tipos de dança) e eixos temáticos? Em quais contextos e com que finalidades a dança voltada à pessoa com deficiência vem sendo desenvolvida/aplicada no Brasil? 
Tendo em vista a necessidade de um mapeamento da produção científica envolvendo o estudo da interface "dança e deficiência" no Brasil, realizou-se um levantamento bibliográfico com base em teses e dissertações acerca do tema em questão. Assim, esse estudo tem como objetivo identificar, conhecer e analisar a produção científica acerca da interface "dança e deficiência" em teses e dissertações nacionais.

\section{Método}

O presente estudo, com enfoque misto (qualitativo e quantitativo) (SAMPIERI; COLLADO; LUCIO, 2006), caracteriza-se como uma pesquisa bibliográfica (MARCONI; LAKATOS, 2008), pois foram utilizados dados referentes à produção do conhecimento publicados em dissertações e teses disponíveis no Banco de Teses da Capes on line e no portal da Biblioteca Digital de Teses e Dissertações (BDTD) do Instituto Brasileiro de Informação em Ciência e Tecnologia (IBICT), sem delimitação de período. Esse levantamento foi realizado durante os meses de janeiro e fevereiro de 2013. Ressalta-se que o Banco de Teses da Capes e o portal da BDTD foram utilizados nesta pesquisa por serem considerados os mais representativos no âmbito das dissertações e teses nacionais, pela facilidade de acesso em meio digital e pela disponibilidade dos documentos (teses e dissertações) on line e na íntegra.

O desenvolvimento dessa pesquisa bibliográfica seguiu quatro etapas, que são descritas por Marconi e Lakatos (2008) como: identificação, que compreende o reconhecimento do assunto; a localização, referente à busca em bibliotecas e fontes on line acerca do objeto de estudo; compilação, momento em que o material encontrado é sistematizado, e fichamento, referente à transcrição dos dados mantendo a fidedignidade dos mesmos.

A busca foi realizada por meio dos descritores "dança" e "deficiência", que são o objeto de investigação do presente estudo. Os critérios de inclusão permearam os seguintes itens: presença dos 
unitermos dança e deficiência no resumo; a pertinência da temática ao escopo do estudo (dança voltada a pessoas com deficiência) e os documentos estarem disponíveis na íntegra.

Após o levantamento dos dados e seleção das teses e dissertações, as informações foram compiladas para a realização do fichamento, sendo registrados: o nome do autor, o ano de defesa, a titulação (mestrado ou doutorado), a subárea em que foi desenvolvida a pesquisa, a característica da população estudada, a abordagem metodológica, o aporte teórico para os estudos que desenvolveram programas de dança, os eixos temáticos abordados no estudo e os tipos de dança, verificando seu contexto e sua finalidade. Em seguida, os dados foram tabelados, dispostos em gráficos e analisados de forma descritiva.

Para a análise e categorização da abordagem metodológica e dos eixos temáticos, foi utilizado como base o sistema de classificação proposto pela Análise Crítica em Produção Discente (PRODISC) ${ }^{2}$. Com relação aos eixos temáticos foram identificados cinco dos 14 que são descritos pelo PRODISC, sendo eles: I. Ensinoaprendizagem (estudos acerca do processo de ensino e aprendizagem da dança para pessoas com deficiência); II. Autopercepção (estudos em que a própria pessoa com deficiência descreve e analisa aspectos acerca de sua vida e de suas relações sociais envolvendo a prática da dança); III. Atitude/percepção (estudos acerca das ideias, sentimentos, valores, concepções, expectativas e representações sociais que profissionais e/ou familiares apresentam sobre as pessoas com deficiência que praticam dança); IV. Identificação/característica (estudos que envolvem a identificação e/ou caracterização referente à dança e/ou à corporeidade da pessoa com deficiência) e V. Reabilitação e saúde (fatores da saúde e procedimentos de reabilitação tendo como meio a dança).

\footnotetext{
${ }^{2} \mathrm{O}$ PRODISC é um projeto financiado pela Fapesp e desenvolvido por Leila R. D'Oliveira de P. Nunes (UERJ), Rosana Glat (UERJ), Júlio R. Ferreira (UNIMEP) e Enicéia Gomes Mendes (UFSCar), que tem como finalidade analisar a produção discente em programas de pósgraduação voltados para pessoas com necessidades educacionais especiais, identificando os temas estudados, tendências teóricas e metodológicas, principais descobertas na área, bem como as lacunas desses estudos (SILVA, 2004).
} 
Quanto à abordagem metodológica, baseada também no sistema proposto pelo PRODISC, foram identificadas: a) histórica (reconstruir o passado de forma objetiva e acurada acerca da dança); b) descritiva (descrever sistematicamente os fatos e as características de uma dada população); c) estudo de caso (o estudo intensivo do estado atual e interações ambientais de um indivíduo, grupo, instituição ou comunidade); d) experimental (relações de causa e efeito através da exposição de um ou mais grupos experimentais submetidos a um tratamento) ee) pesquisa ação (desenvolvimento de novas habilidades ou abordagens com aplicação direta no trabalho). Além dessas abordagens descritas pelo PRODISC, foram identificadas também as pesquisas etnográfica e fenomenológica, definidas de acordo com os autores das dissertações e teses.

Quanto aos tipos de dança, a identificação foi estabelecida com base na análise e categorização no contexto em que foi desenvolvida a dança e na sua finalidade. Para esse estudo foram propostas as seguintes categorizações: a) contexto educacional com finalidade pedagógica; b) contexto artístico com finalidade acerca da performance do bailarino; c) contexto de reabilitação com finalidade terapêutica e d) contexto esportivo, com a finalidade envolvendo os aspectos competitivos da técnica e/ou do rendimento do bailarino. Como já foi dito, a relação entre que tais contextos e finalidades não são rígidas, podendo-se encontrar estudos que envolvem o contexto educacional, por exemplo, mas que possuem uma finalidade terapêutica, competitiva ou de performance.

\section{Resultados}

Foram encontradas 50 teses e dissertações por meio dos descritores "dança" e "deficiência". Todavia, nesse levantamento inicial, o termo deficiência também designava o déficit de estudos em dança ou a falta de conhecimento/formação dos profissionais em dança, ou seja, não referenciavam a deficiência enquanto etiologia (física, intelectual, visual ou auditiva). Após essa seleção, foram 
encontradas 35 produções acadêmicas que atendiam ao objeto de estudo, sendo 28 dissertações de mestrado e sete teses de doutorado. A quantidade de dissertações e teses defendidas por ano é apresentada na Figura 1.

Figura 1 - Quantidade de dissertações e teses por ano

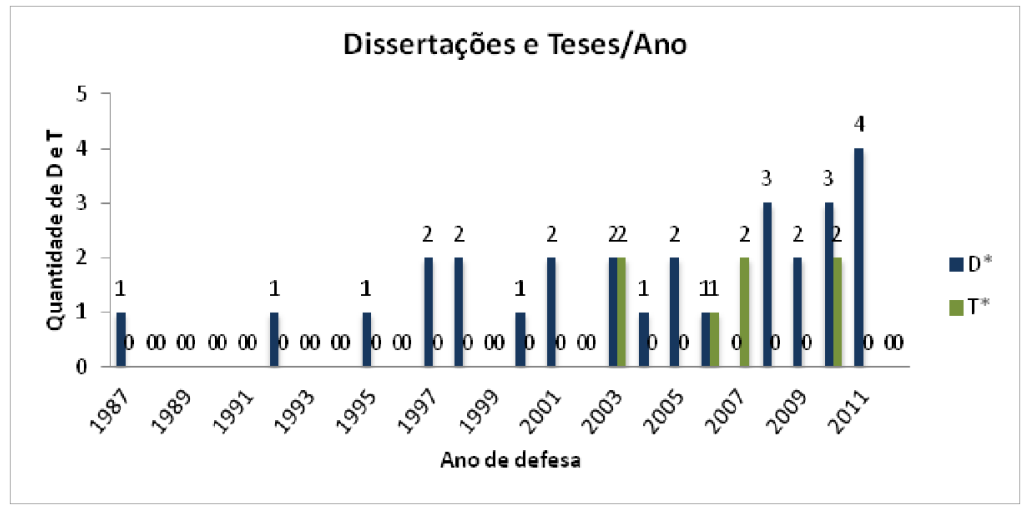

Fonte: Elaborado pelo autor.

$* \mathrm{D}=$ Dissertações $/ \mathrm{T}=$ Teses.

Segundo as informações disponibilizadas pelo Banco de Teses da Capes e pelo portal da BDTD, o marco em pesquisas que envolvem a dança para pessoas com deficiência data de 1987, com a publicação da primeira dissertação intitulada "Dança-arte do movimento para crianças com deficiência auditiva", desenvolvida pela pesquisadora Maria Renata de Macedo Neves. Já as teses de doutorado tiveram início em 2003, pelas pesquisadoras Eliana Lucia Ferreira e Rosana Carla Gonçalves Gomes Cintra, com as teses intituladas respectivamente "Corpo-movimento-deficiência: as formas dos discursos da/na dança em cadeira de rodas e seus processos" e "A comunicação do corpo deficiente: a dança como dissolução de estigma". A Figura 1 também apresenta um aumento das produções acadêmicas desde 1987 até 2012, sendo que nos últimos cinco anos verifica-se um aumento significativo acerca dessa temática. Ressalta-se que o ano de 2012 não apresentou nenhuma produção científica sobre o tema, o que pode ter ocorrido pelo fato 
de as dissertações e teses referentes a esse ano ainda não terem sido depositadas nos respectivos bancos até o momento do levantamento dos dados

Além da quantidade das produções científicas publicadas no país, foi identificado em quais subáreas do conhecimento foram desenvolvidas tais pesquisas, as características da população, a abordagem metodológica, o aporte teórico das pesquisas que desenvolveram programas de dança, os eixos temáticos abordados no estudo e os tipos da dança, verificando seu contexto e sua finalidade.

As subáreas identificadas foram: Dança/Artes Cênicas (12), Educação (8), Educação Física (7), Comunicação e Semiótica (5) e Outros (3), demonstrando a interdisciplinaridade da dança.

Com relação às características da população foram identificadas duas informações, uma referente ao tipo de deficiência e outra referente à fase do desenvolvimento em que os participantes da pesquisa se encontravam. Quanto à deficiência, foram identificados estudos que envolveram a física, a visual, a auditiva e a intelectual, além de dois estudos que trataram a dança para grupos que envolviam mais de um tipo de deficiência. Quanto às fases do desenvolvimento, foram identificados estudos voltados para adultos, crianças e adolescentes, além de quatro estudos que envolveram mais de uma fase e três estudos em que não foi possível identificá-la. Tais informações são divulgadas na tabela 1 .

Tabela 1 - Características da população estudada nas teses e dissertações

\begin{tabular}{lcccccc}
\hline & Adulto & Adolescente & Criança & $\begin{array}{l}\text { Mais de uma } \\
\text { faixa etária }\end{array}$ & $\begin{array}{l}\text { Não } \\
\text { identificado }\end{array}$ & Total \\
\hline DF* & 18 & 0 & 0 & 1 & 1 & 20 \\
\hline DV* & 3 & 0 & 1 & 2 & 0 & 6 \\
DA $^{*}$ & 0 & 2 & 2 & 0 & 0 & 4 \\
DI* & 1 & 0 & 0 & 0 & 2 & 3 \\
$\begin{array}{l}\text { Mais de } \\
\text { uma } \\
\text { deficiência }\end{array}$ & 1 & 0 & 0 & 1 & 0 & 2 \\
& 23 & 2 & 3 & 4 & & 35 \\
\hline
\end{tabular}

Fonte: Elaborado pelo autor.

*DF $=$ deficiência física / DV $=$ deficiência visual / DA = deficiência auditiva / DI = deficiência intelectual. 
Nota-se que estudos sobre dança foram desenvolvidos para adultos com deficiência (23) com maior proporção para os que possuem deficiência física (18). Pequena parcela dos estudos foi direcionada para adolescentes (2) e crianças (3), sendo que estes envolveram a deficiência auditiva e visual. De modo geral, não houve evidência acerca da deficiência auditiva, visual e intelectual.

Quanto à abordagem metodológica, foram destacados estudos que envolveram o estudo de caso, a pesquisa descritiva, a etnográfica, a experimental, a fenomenológica, a histórica e a pesquisa ação. A quantidade referente a essas abordagens metodológicas é apresentada na Figura 2.

Figura 2 - Quantidade de dissertações e teses pelas abordagens metodológicas

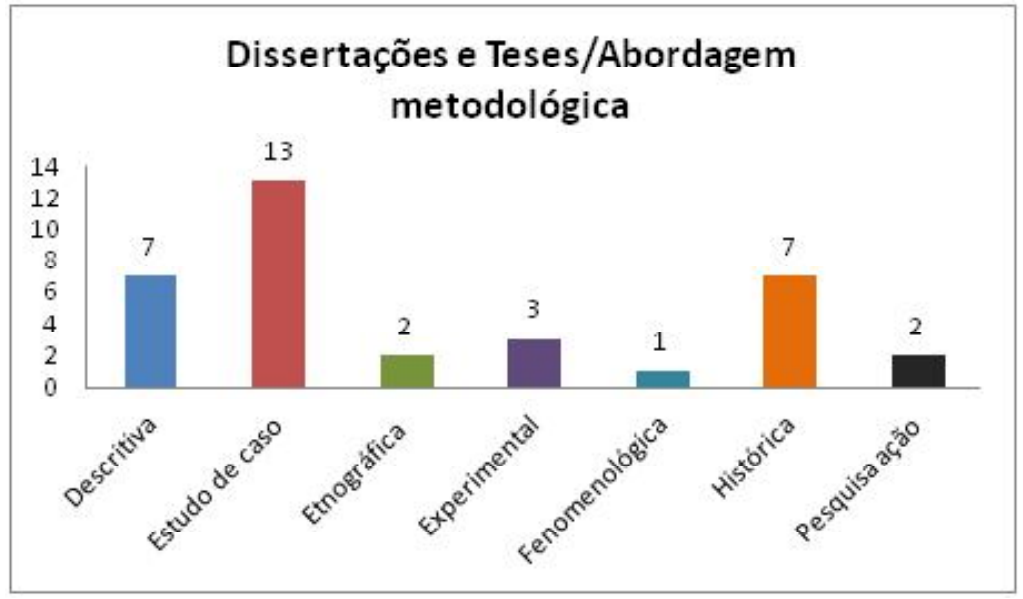

Fonte: Elaborado pelo autor.

Verifica-se que preponderou o desenvolvimento do estudo de caso (13), seguido da pesquisa descritiva (7) e da pesquisa histórica (7). Outros estudos, sendo estes em menor proporção, envolveram a pesquisa experimental (3), a etnográfica (2), a pesquisa ação (2) e a fenomenológica (1). Ressalta-se que, desses 35 estudos, apenas dois apresentaram o enfoque quantitativo, sendo todos os outros com 
enfoque qualitativo ou misto. Além disso, do total de estudos, 17 desenvolveram pesquisa intervenção, ou seja, desenvolveram programas de dança para pessoas com deficiência.

Com relação aos 17 estudos que desenvolveram programas de dança, foi evidenciada a preocupação com o processo de ensino e aprendizagem das pessoas com deficiência, totalizando 12 estudos. Já estudos que envolveram os aspectos acerca da reabilitação dessas pessoas (4) e de sua performance (1) durante apresentações em festivais de dança, representaram uma pequena parcela.

Quanto ao aporte teórico utilizado por esses estudos para desenvolver seus programas, verifica-se que três deles fundamentaram-se em Rudolf Laban, um fundamentou-se em Bartenieff, um envolveu os princípios da teoria Contato Improvisação, nove fundamentaram-se em mais de um autor e, em três, não foi possível identificar o aporte teórico. Ressalta-se que desses nove estudos que associaram mais de um autor, quatro envolveram Laban. Quanto aos demais autores, destacam-se: Feldenkrais, Graham, Bartenieff, Alexander, Fux, Pilates, Freire, Merleau Ponty, Dalcroze, Damásio e Reich. De modo geral, Laban demonstra ser um dos autores mais presente nas pesquisas que desenvolveram programas de dança para pessoas com deficiência.

Ressalta-se que há dificuldade em realizar uma categorização desses autores, visto que eles pertencem a uma área, por exemplo, a Dança, mas também envolvem outra, como a da Saúde, para ampliar seus conhecimentos. Um exemplo é Maria Fux, bailarina que passou a envolver a área da reabilitação, propondo a dançaterapia. Além disso, os autores das dissertações e teses em questão usaram, por exemplo, teóricos da educação para desenvolver estudos em dança e teóricos da dança para desenvolver estudos acerca da reabilitação.

Ao tratar-se das temáticas abordadas pelas dissertações e teses, foram identificados cinco eixos. A Figura 3 apresenta a quantidade de dissertações e teses que abordaram cada um dos eixos temáticos. 
Figura 3 - Temáticas abordadas pelas dissertações e teses

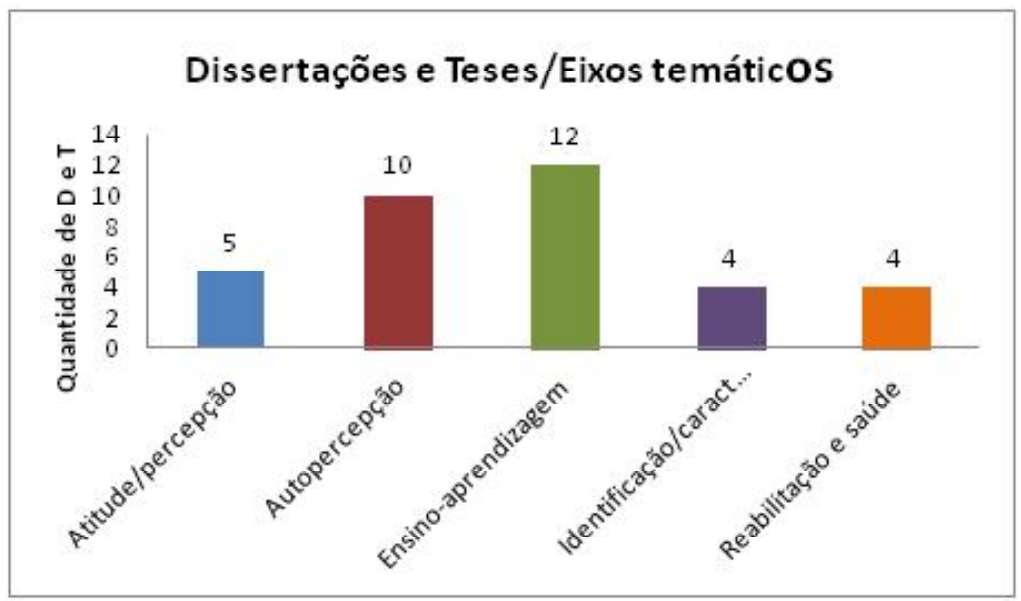

Fonte: Elaborado pelo autor.

Nos estudos apresentados preponderou a investigação do processo de ensino e aprendizagem da dança para as pessoas com deficiência (12) e da autopercepção dos que praticam essa atividade (10), sendo esses temas destacados desde os primeiros estudos em 1987, demonstrando predominância ao longo desses 25 anos. Em menor evidência aparecem estudos que abordaram atitude/percepção (5) e identificação/característica (4) da dança para pessoas com deficiência. Ressalta-se que o eixo reabilitação e saúde apresentou certa evidência nos últimos cinco anos (2007-2012).

Quanto às danças que foram desenvolvidas nas dissertações e teses, foi possível identificar 11 tipos diferentes, além de 11 estudos nos quais não foi possível identificar qual característica da dança foi desenvolvida pelos autores. Esse resultado é apresentado na Figura 4. 
Figura 4 - Tipos de danças desenvolvidas pelas dissertações e teses

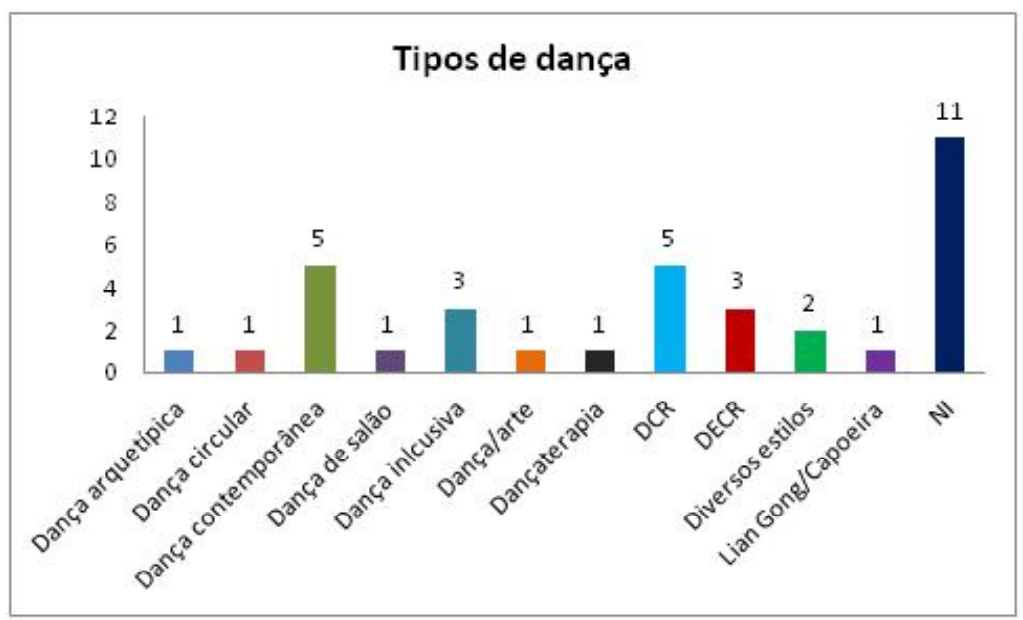

Fonte: Elaborado pelo autor.

*DCR - Dança em Cadeira de Rodas/ DECR - Dança Esportiva em Cadeira de Rodas.

Houve estudos que especificaram a dança enquanto contemporânea (5) e DCR (5). Em menor proporção, verifica-se o desenvolvimento da dança inclusiva (3) e da DECR (3), além de outras sete danças diferentes. Esses tipos de dança totalizam 24 estudos. Desses, dois envolveram em sua pesquisa uma dança que desenvolvia mais de um estilo. Além disso, é importante ressaltar os 11 estudos em que não foi possível identificar as características da dança. Tal resultado sugere a dificuldade em compreender todas as manifestações da dança e como elas se relacionam entre si.

Dessa forma, ao verificar a dificuldade em definir e/ou identificar o tipo de dança, seja para pessoas com deficiência ou não, foi desenvolvida especificamente para esse estudo a classificação da dança de acordo com o seu contexto e sua finalidade. Tal classificação foi proposta para compreender melhor de que forma as danças são desenvolvidas para as pessoas com deficiência, sem especificar sua forma, tipo, estilo ou denominação. Ou seja, não importa se está sendo desenvolvida a dança de salão, dança contemporânea ou DCR, e sim "o porquê", "onde" e "para quem" está sendo desenvolvida. 
Neste estudo, o "para quem" apresenta-se bem claro e definido: crianças, adolescentes e/ou adultos com deficiência física, auditiva, visual e/ou intelectual. Já o "onde" seria o contexto em que se insere a dança e "o porquê" seria com que finalidade essa dança está sendo desenvolvida.

Assim, a partir da leitura dos estudos, foram realizadas duas categorizações: 1) referente ao contexto - educacional (escolas), artístico (grupos de profissionais ou amadores de dança, espetáculos, festivais), de reabilitação (clínicas) e esportivo (competições de dança) e 2) referente à finalidade - pedagógica, de performance, terapêutica e competitiva. Na maioria das vezes, o contexto educacional estará vinculado à finalidade pedagógica; o contexto artístico à finalidade acerca da performance do bailarino; o contexto de reabilitação à finalidade terapêutica e o contexto esportivo à finalidade que envolve os aspectos competitivos e/ou do rendimento do bailarino.

Após a categorização dos achados com base nesses aspectos, foi possível verificar qual a proporção de estudos envolvendo determinados contextos e finalidades. Tal resultado é observado na tabela 2 .

Tabela 2 - O contexto relacionado às finalidades acerca da dança para pessoas com deficiência nas teses e dissertações

\begin{tabular}{lcccccc}
\hline CONTEXTOS & \multicolumn{5}{c}{ FINALIDADES } \\
\hline & Performance & Pedagógica & Terapêutica & $\begin{array}{c}\text { Competitiva/ } \\
\text { Alto rendimento }\end{array}$ & NI & Total \\
Artístico & 13 & 1 & 0 & 0 & 0 & 14 \\
Educacional & 0 & 12 & 1 & 0 & 0 & 13 \\
Esportivo & 0 & 0 & 0 & 3 & 0 & 3 \\
Reabilitação & 0 & 0 & 4 & 0 & 0 & 4 \\
NI & 0 & 0 & 0 & 0 & 1 & 1 \\
Total & 13 & 13 & 5 & 3 & 1 & 35 \\
\hline
\end{tabular}

Fonte: Elaborado pelo autor.

Verificou-se que há predominância do contexto artístico e educacional e, respectivamente, das finalidades acerca da performance da pessoa com deficiência e pedagógica. Não houve evidência acerca do contexto esportivo, do contexto de reabilitação, da finalidade competitiva e da finalidade terapêutica. Há que atentar- 
se que dois estudos envolveram contextos e finalidades distintas: um estudo envolveu o contexto artístico, mas com uma finalidade pedagógica e um estudo envolveu o contexto educacional com uma finalidade terapêutica. Ressalta-se que em apenas um estudo não possível identificar o contexto e a finalidade da dança para pessoas com deficiência. Tais resultados demonstram novamente a preocupação com o processo de ensino e aprendizagem das pessoas com deficiência por meio da dança e, também, o envolvimento dessas pessoas acerca do mundo artístico em apresentações em festivais, espetáculos e a inserção em grupos profissionais de dança.

\section{Discussão}

O crescente número de pesquisas nos últimos cinco anos que envolvem a temática em questão relaciona-se à implantação de inúmeros cursos em nível superior e de pós-graduação, que, segundo Mendes (2010), incentivou pesquisas acerca da educação especial e das pessoas com deficiência. Além disso, Freire (2001) refere-se às novas propostas de trabalho que passaram a ser elaboradas com a finalidade de explorar e respeitar corpos diferentes no âmbito da dança.

Os estudos em dança para pessoas com deficiência foram desenvolvidos em diversas subáreas, não se restringindo apenas à área da Dança e das Artes Cênicas, demonstrando a interdisciplinaridade com que esse conteúdo é abordado, ou seja, sua capacidade de abranger duas ou mais áreas (subáreas) de modo que sejam estabelecidos discursos que relacionem cada uma delas, buscando conceitos, métodos e estruturas teóricas com a finalidade de proporcionar um enriquecimento mútuo (SCHMITT et al., 2006).

As pesquisas desenvolvidas sobre dança para pessoas com deficiência envolvem, em sua maioria, população de adultos com deficiência física. Tal resultado corresponde aos dados do Censo 2010 (INSTITUTO BRASILEIRO DE GEOGRAGIA E 
ESTATISTICA, 2013), os quais indicam que a deficiência física é a segunda com maior incidência na população brasileira (7\%), sendo que o maior contingente ocorre na população de 40 a 59 anos.

Por outro lado, pequena parcela dos estudos foi desenvolvida com crianças e adolescentes e com as demais deficiências (visual, auditiva e intelectual). O Censo 2010 (INSTITUTO BRASILEIRO DE GEOGRAGIA E ESTATISTICA, 2013) apresenta que apenas $7,4 \%$ da população possui alguma deficiência com faixa etária entre 0 e 14 anos. Há também, há baixa incidência de pessoas com deficiência auditiva $(5,1 \%)$ e intelectual $(1,4 \%)$. Embora os dados apontem alta incidência para adultos com deficiência física na população brasileira, infere-se que mais estudos deveriam ser desenvolvidos envolvendo crianças e adolescentes e pessoas com deficiência visual, auditiva e intelectual.

Esses apontamentos também se relacionam com o fato de a maioria das pesquisas ter desenvolvido o estudo de caso, pois, como Gil (2008) descreve, o estudo de caso torna-se um método eficaz quando possui um único sujeito participante da pesquisa ou múltiplos casos com base frágil para a generalização, possibilitando assim a expansão de proposições teóricas acerca do tema e da população que se quer estudar.

Isso reflete nas populações marcadas pela heterogeneidade, presente nas amostras compostas por pessoas com deficiência, não permitindo a generalização dos resultados. Afinal, duas pessoas com o mesmo diagnóstico podem apresentar experiências e limitações diferentes, o que dificulta encontrar um grupo homogêneo para que estudos experimentais sejam desenvolvidos. Sendo assim, estudos de caso e estudos com enfoque qualitativo demonstram a preferência dos pesquisadores nessa área.

Com relação ao aporte teórico, mesmo diante de tanta variedade, há que se destacar o estudioso Rudolf Laban, que foi considerado como base por metade das pesquisas que envolveram programas de 
dança. Esse fato é justificado pela maneira de esse autor referir-se à dança como um meio para educar, com base em movimentos naturais e espontâneos, orientados e estruturados, proporcionando assim, o desenvolvimento de cada um (LABAN, 1990), para que se tornem pessoas livres e capazes de expressar sua criatividade e a consciência do fluxo natural do movimento humano (MARQUES, 2002), uma abordagem ampla e abrangente.

Ao longo dos últimos 25 anos, os estudos que envolveram pessoas com deficiência e a dança demonstraram evidência acerca da temática que envolve o processo de ensino e aprendizagem. Tais estudos são importantes pois envolvem a ação do professor no sentido de despertar e orientar o aluno para o movimento livre e para técnicas de diversas danças (SILVEIRA, 2009, MARQUES, 2002), proporcionando o conhecimento teórico e prático durante o processo de intervenção, além de colaborar para uma ação consciente, reflexiva e que respeite a individualidade de cada aluno, visando o processo de ensino e aprendizagem (BERNABÉ, 2001).

Esse resultado também está relacionado com o número de pesquisas que foram desenvolvidas em Programas de Pós-graduação em Educação, como citado anteriormente, e pelo aporte teórico com base, especialmente, em Rudolf Laban, que tratava a educação por meio da dança.

Outro tema relevante desenvolvido foi aquele acerca da autopercepção da pessoa com deficiência, que tem como finalidade compreender, descrever, analisar e refletir a experiência pessoal, com base em relatos e entrevistas (SILVA, 2004). Segundo Gil (2008), a vantagem desses instrumentos envolve a obtenção de dados diversos acerca do aspecto da vida social, sendo eficiente para aprofundar o conhecimento acerca do comportamento humano.

Assim, tais estudos são importantes pois se preocupam em dar a voz às pessoas com deficiência para que possam relatar vários aspectos, como aqueles que refletem como a dança influencia suas vidas e suas relações sociais, como compreendem o corpo deficiente que dança e o significado dela para si. 
Ressalta-se também que, nos últimos cinco anos, houve a preocupação com temas que envolveram aspectos acerca da saúde, fazendo da dança um agente importante para a melhoria da qualidade de vida das pessoas com deficiência. Segundo Machado (2010), a dança atua como integradora corporal, viabilizando o ajuste postural e funcional, que influenciam de forma positiva na regulação e orientação dos mecanismos essenciais para o movimento, além de melhorar aspectos sociais e emocionais.

Outros estudos também corroboram com esses dados, demonstrando como a dança beneficiou o comportamento; a autoestima; a saúde mental (SANTOS; BRAGA, 2010, SILVA; CARVALHO; NETO, 2009); aspectos motores, como o equilíbrio e a organização postural, e aspectos cognitivos e interativos (MAIA, 2012) de pessoas com deficiência física.

Quanto aos tipos de dança, várias delas foram desenvolvidas para as pessoas com deficiência, todavia, duas delas demonstraram maior incidência: a dança contemporânea e a Dança em Cadeira de Rodas (DCR).

O número de estudos que envolveram a dança contemporânea é justificado pelo fato de essa dança ter inovado pensamentos e maneiras de se movimentar desde a década de 80, estabelecendo um discurso próprio. Além disso, pelo fato de abarcar corpos heterogêneos, proporcionar a interface com outras áreas de conhecimento e refletir sobre questões sociais (MATOS, 2006).

Já a DCR teve início no Brasil a partir da década de 90, tendo como principal finalidade a competitiva. O número de estudos envolvidos está relacionado com o fato de essa ser uma dança especificamente voltada às pessoas com deficiência física (FERREIRA; FERREIRA, 2004), sendo esta a maior população envolvida nos estudos em dança para pessoas com deficiência. Observa-se que essa DCR pode possuir um caráter esportivo e de competição, sendo denominado de Dança Esportiva em Cadeira de Rodas (DECR); todavia, vários estudos apresentaram as técnicas e fundamentos dessa prática com a finalidade artística e pedagógica, 
deixando de lado critérios esportivos para focar nos potenciais das pessoas e em suas poéticas e demonstrar a arte por meio da complexidade entre o corpo do bailarino cadeirante e suas potencialidades (CORREA, 2007).

Os resultados apontaram que o contexto artístico e a finalidade acerca da performance do bailarino com deficiência apresentaram grande evidência, juntamente com o contexto educacional e a finalidade pedagógica. Quanto ao contexto artístico e a finalidade acerca da performance, essa evidência está relacionada com o surgimento de novos grupos profissionais em dança que envolvem pessoas com deficiência em seu corpo de trabalho. Correa (2007) explana que tais grupos enfatizam os movimentos singulares de cada corpo com deficiência, com olhares para uma nova estética e para corpos diferentes, além de incentivar a profissionalização e a manifestação artística da dança para essas pessoas.

Já o resultado acerca do contexto educacional e da finalidade pedagógica corrobora com os apontamentos anteriores apresentados nesta discussão, relacionando o número de pesquisas desenvolvidas em Programas de Pós-graduação em Educação, o aporte teórico com base em Rudolf Laban, com evidências acerca da temática que envolve o processo de ensino e aprendizagem.

\section{Considerações finAS}

Foram encontradas 35 produções científicas envolvendo dança para pessoas com deficiência (28 dissertações e 7 teses), com prevalência de estudos junto à população de adultos com deficiência física; predominância de pesquisas envolvendo estudos de caso e aporte teórico com base em Rudolf Laban; quanto ao eixo temático, prepondera a ênfase em processos de ensino-aprendizagem da dança para pessoas com deficiência; maior evidência à dança contemporânea e dança em cadeira de rodas; e o predomínio da dança desenvolvida nos contextos artístico e educacional e com as finalidades acerca da performance e pedagógica. 
Com isso, foi possível reconhecer as principais tendências científicas envolvendo dança para pessoas com deficiência, identificar o caminho que esses estudos vêm trilhando no Brasil, bem como as lacunas existentes na área. Dessa forma, sugere-se que novos estudos sejam desenvolvidos abarcando populações com deficiências sensoriais e intelectuais; envolvendo pessoas em fases iniciais do desenvolvimento; emprego de diferentes metodologias e eixos temáticos diversificados e exploração de contextos e finalidades distintas. 
Dance and disabilities: a bibliographic study in theses and dissertations from Brazil

Abstract: This study aims to identify and analyze the scientific production related to dance for physically disabled persons in nationwide thesis and dissertations. The results demonstrate: an increase in production during the past 5 years; a prevalence of studies involving the population of physically disabled adults; a predominance of research involving case study and Laban as theoretical contribution; concerning thematic line, the teaching-learning process of dance for disabled persons prevails; greater emphasis is given to contemporary dance and wheelchair dance. Therefore, it was possible to recognize the leading scientific tendencies related to dance for physically disabled persons.

Keywords: Dance. Disability. Scientific production.

Danza y discapacidad: una revisión bibliográfica en las tesis y disertaciones brasileñas

Resumen: Este estudio tiene como objetivo identificar y analizar la producción científica sobre la danza para personas con discapacidad en las tesis y disertaciones brasileñas. Los resultados mostraran: aumento de la producción en los ultimos cinco años; mayoría de estudios con la población de adultos con discapacidades físicas; predominio de la investigación con estudio de casos y Labán como apoyo teórico; como el tema principal, prepondera la enseñanza y el aprendizaje de la danza; mayor evidencia a la danza contemporánea y la danza en silla de ruedas. Fue posible reconocer las principales tendencias científicas que involucran danza y discapacidad.

Palabras clave: Danza. Discapacidad. Producción cientifica. 


\section{REFERÊNCIAS}

BERNABÉ, R. Dança e deficiência: proposta de ensino. 2001. 97 f. Dissertação (Mestrado em Educação Física) - Faculdade de Educação Física, Universidade Estadual de Campinas, Campinas, 2001.

COORDENAÇÃO DEAPERFEIÇOAMENTO DE PESSOALDE NÍVELSUPERIOR. Banco de Teses. Disponível em: <http://capesdw.capes.gov.br/capesdw/>. Acesso em: 28 fev. 2013.

CORREA, F. D. C. Corpo sitiado..., a comunicação invisível: dança, rodas e poéticas. 2007. 141f. Tese (Doutorado em Comunicação e Semiótica) - Pontifícia Universidade Católica de São Paulo, São Paulo, 2007.

FERREIRA, E. L. O sentido do sentir: corpos dançantes em cadeiras de rodas. Revista Conexões, Campinas, v. 0, n. 4, p. 89-98, 2000.

FERREIRA, E. L.; FERREIRA, M. B. R. A possibilidade do movimento corporal na dança em cadeira de rodas. Revista Brasileira de Ciência e Movimento, Brasília, v. 12, n. 4, p. 13-17, 2004.

FREIRE, I. M. Dança-educação: o corpo e o movimento no espaço do conhecimento. Cadernos Cedes, Campinas, v. 21, n. 53, p. 31-55, 2001.

FREIRE, I. M. Na dança contemporânea, cegueira não é escuridão. Revista Ponto de Vista, Florianópolis, n. 6, p. 57-78, 2005.

GIL, A. C. Métodos e técnicas de pesquisa social. 6. ed. São Paulo: Átlas, 2008.

INSTITUTO BRASILEIRO DE GEOGRAGIA E ESTATISTICA. Censo demográfico 2010. Disponivel em: <http://www.ibge.gov.br/home/presidencia/noticias/ noticia_visualiza.php?id_noticia=2125\&id_pagina=1 >. Acesso em: 24 jan. 2013.

JOSEPH, T. W. R. Entre a dança e a língua de sinais, a caixa mágica da criação: possibilidades interativas para dança com surdos e ouvintes. 2010. 188 f. Tese (Doutorado em Artes) - Instituto de Artes, Universidade Estadual de Campinas, Campinas, 2010.

LABAN, R. Dança educativa moderna. São Paulo: Ícone, 1990.

MACHADO, L. T. A. A dançaterapia melhora a qualidade de vida e a função neuromuscular de indivíduos com transtornos neuromotores. 2010. 137 f. Dissertação (Mestrado em Ciências da Saúde) - Núcleo de Pós-Graduação em Medicina, Universidade Federal de Sergipe, Aracaju, 2010.

MAIA, E. T. A dança como instrumento de intervenção neuropsicológica em crianças com encefalopatia crônica não progressiva: um estudo etológico não controlado. 2012. 74 f. Dissertação (Mestrado em Ciência do Comportamento) - Departamento de Processos Psicológicos Básicos, Universidade de Brasília, Brasília, 2012. 
MARCONI, M. A.; LAKATOS, E. V. Técnicas de pesquisa: planejamento e execução de pesquisas, amostragens e técnicas de pesquisa, elaboração e interpretação de dados. 7. ed. São Paulo: Atlas, 2008.

MARQUES, I. A. Revisitando a dança educativa moderna de Rudolf Laban. Revista Sala Preta, São Paulo, v. 2, n. 1, 2002, p. 276-281.

MATOS, L. H. A. Cartografando múltiplos corpos dançantes: a construção de novos territórios corporais e estéticos na dança contemporânea brasileira. 2006. 186 f. Tese (Doutorado em Artes cênicas) - Programa de Pós-Graduação em Artes Cênicas, Universidade Federal da Bahia, Salvador, 2006.

MAUERBERG-DECASTRO, E. Atividade física adaptada. Ribeirão Preto: Tecmedd, 2005.

MENDES, E. G. A radicalização do debate sobre inclusão escolar no Brasil. Revista Brasileira de Educação, Rio de Janeiro, v. 11, n. 33, p. 387-559, 2006.

MENDES, E. G. Breve histórico da educação especial no Brasil. Revista Educación y Pedagogía, Medellín, v. 22, n. 57, p. 93-109, 2010.

PAULA, O. R. Intensidade de esforço na competição de dança esportiva em cadeira de rodas. 2010. 56 f. Dissertação (Mestrado em Educação Física) Faculdade de Educação Física e Desportos, Universidade Federal de Juiz de Fora, Juiz de Fora, 2010.

PEDRINELLI, V. J.; VERENGUER, R. C. G. Educação física adaptada: introdução ao universo de possibilidades. In: GORGATTI, M. G.; COSTA, R. F. (Org.). Atividade física adaptada: qualidade de vida para pessoas com necessidades especiais. 2. ed. Barueri: Manole, 2008. p. 1-27.

SAMPIERI, R.H.; COLLADO, C.H.; LUCIO, P.B. Metodologia de pesquisa. São Paulo: McGraw-Hill, 2006.

SANTOS, L. B.; BRAGA, D. A. Dança e fisioterapia para crianças e adolescentes com paralisia cerebral. Revista Neurociência, São Paulo, v. 18, n. 4, p. 437-442, 2010.

SILVA, F.; CARVALHO, B. A.; NETO, A. R. M. Dança em cadeira de rodas e paralisia cerebral: estudo de caso da menina Laura. Revista Conexões, Campinas, v. 7, n. 1, p. 121-134, 2009.

SILVEIRA, S. S. Técnica $\mathbf{e}(\mathbf{m})$ criação somática: uma proposta corporal par artistas cênicos com (d)eficiência física através dos princípios e fundamentos corporais Bartenieff. 2009, 234 f. Dissertação (Mestrado em Artes Cênicas) Escola de Teatro e Dança, Universidade Federal da Bahia, Salvador, 2009.

SCHMITT, V.; TRAVASSOS, L. P.; FIALHO, F. A. P.; REMOR, C. A. M. Interdisciplinaridade de pós-graduação. Revista de Biologia e Ciências da Terra, Campina Grande, v. 6, n. 2, p. 295-304, 2006. 
SILVA, R. H. R. Análise epistemológica das dissertações e teses defendidas no Programa de Pós-Graduação em Educação Especial da UFSCar: 1981-2002. 2006. 193 f. Dissertação (Mestrado em Educação Especial) Programa de Pós-Graduação em Educação Especial, Universidade Federal de São Carlos, São Carlos, 2004.

SOUZA, J. H. A arte da dança de salão e seus aspectos terapêuticos: um estudo de caso no instituto de educação para a vida Blanca Nieve, Monte Mor/SP. 2011. 164 f. Dissertação (Mestrado em Educação) - Faculdade de Educação, Universidade Estadual de Campinas, Campinas, 2011.

Endereço para correspondência:

Patricia Rossi

Rua Carvalho Filho, n. 1529, Fonte

Araraquara - SP

CEP: $14802-412$

Recebido em: 19.04.2013

Aprovado em: 22.08.2013

Movimento, Porto Alegre, v. 19, n. 04, p. 181-205, out/dez de 2013. 